\title{
Probiotics, prebiotics, and synbiotics regulate the intestinal microbiota differentially and restore the relative abundance of specific gut microorganisms
}

\author{
Chen Li, ${ }^{1 *}$ ○ Zhihua Niu, ${ }^{1 *}$ Meijuan Zou, ${ }^{1 *}$ Suyue Liu, ${ }^{1}$ Miaoshu Wang, ${ }^{2}$ Xinxi Gu, ${ }^{1}$ Haiqiang Lu, ${ }^{1}$ \\ Hongtao Tian, ${ }^{1,3} \dagger$ ( $)$ and Rajesh $\mathrm{Jha}^{4} \dagger$ (1) \\ ${ }^{1}$ College of Food Science and Technology, Agricultural University of Hebei, Baoding, Hebei, 071000, China \\ ${ }^{2}$ New Hope Tensun (Hebei) Dairy Co. Ltd., Baoding, Hebei, 071000, China \\ ${ }^{3}$ National Engineering Research Center for Agriculture in Northern Mountainous Areas, Baoding, Hebei, 071000, China \\ ${ }^{4}$ Department of Human Nutrition, Food and Animal Sciences, College of Tropical Agriculture and Human Resources, \\ University of Hawaii at Manoa, Honolulu 96822
}

\begin{abstract}
Fermented milk is an effective carrier for probiotics, the consumption of which improves host health. The beneficial effects of probiotics, prebiotics, and synbiotics on gut dysbiosis have been reported previously. However, the way in which specific probiotics, prebiotics, and synbiotics regulate intestinal microbes remains unclear. Therefore, the probiotics Lactobacillus rhamnosus AS 1.2466 and Lactobacillus delbrueckii ssp. bulgaricus ATCC 11842 and the prebiotics xylooligosaccharide and red ginseng extracts were fed to mice to determine their effects on the intestinal microbiota. Then, mice were administered xylooligosaccharide and L. rhamnosus (synthesis) by gavage, and the number of L. rhamnosus was determined in the intestine at different times. The results show that probiotics and prebiotics can quickly reduce the Firmicutes/Bacteroidetes ratio, inhibit harmful bacteria (such as Klebsiella and Escherichia coli), and accelerate the recovery of beneficial intestinal microorganisms (such as Lactobacillus). In a complex intestinal microecology, different probiotics and prebiotics have different effects on specific intestinal microorganisms that cannot be recovered in the short term. In addition, after $20 \mathrm{~d}$ of intragastric xylooligosaccharide addition at $0.12 \mathrm{~g} / \mathrm{kg}$ of body weight, L. rhamnosus colonization in the mouse ileum was $7.48 \log \mathrm{cfu} / \mathrm{mL}$, which was higher than in the lowdose group, prolonging colonization time and increasing the number of probiotics in the intestine. Therefore, this study demonstrated that probiotics and prebiot-
\end{abstract}

Received December 3, 2019.

Accepted March 5, 2020.

*These authors contributed equally to this work.

†Corresponding authors: tht631022@163.com and rjha@hawaii.edu ics can promote the balance of intestinal microbiota by regulating specific microbes in the intestine, and the effects of a suitable combination of synbiotics are beneficial, laying the foundation for the development of new dairy products rich in synbiotics.

Key words: growth factor, biotechnology

\section{INTRODUCTION}

The gut microbiota has been of tremendous interest because of its potential association with the health status of the host. An imbalance in certain gut microbiota may give rise to a disturbance in the gut's function, thus causing various diseases. For example, the intestinal microbiota affects the development of the central nervous system through the gut-brain axis and modifications in the gut microbiome can lead to disorders in the central nervous system immune response, which may result in the related diseases such as depression, Parkinson's disease, or schizophrenia (Zhu et al., 2017, 2018a). Similarly, the gut-liver axis can be affected (Konturek et al., 2018), through which disorder in the intestinal microbiota generates the proliferation of harmful bacteria. Subsequently, the accumulation of toxic substances increases the risk of liver damage. Furthermore, abnormalities in the intestinal microbiota can cause diarrhea, intestinal cancer, food allergies, and so on. To some extent, this reveals a strong correlation between intestinal microbiota and human health and indicates that the intestinal microbiota is worthy of much attention. At present, functional foods have been developed to manage the intestinal microecological environment using probiotic and prebiotic supplements.

Based on ongoing research and randomized clinical trials, the use of probiotics and prebiotics has beneficial effects on human health and wellness (Mahasneh and Mahasneh, 2017). One of the known roles of probiotics 
is to regulate the balance of the intestinal microbiota, thus conferring benefits to host health (Sanders, 2008).

Prebiotics can be used in place of probiotics or as an additional supplement, stimulating the growth and activity of beneficial bacteria in the gastrointestinal tract (GIT). In general, natural products such as inulin and lactulose are important sources of prebiotics, which can be added to foods to increase nutrients and enhance health benefits such as the absorption of minerals like calcium and magnesium (Fuchs et al., 2008). Moreover, oral administration of prebiotics can increase beneficial microbiota populations in the GIT to prevent immunemediated destruction (Sohail et al., 2017).

The synergistic combination of probiotics and prebiotics found in products such as foods, drugs, and supplements is known as synbiotics (Mohanty et al., 2018). As early as 1960, researchers noted that synbiotics could be used in nutrition to interfere with the human intestinal microbiota (Turek, 1960). However, no further development occurred because of limitations in technology. Today, with the emergence of advanced technologies such as high-throughput sequencing, research is being done on synbiotics and various metabolic disturbances such as diet-induced obesity (Ke et al., 2019).

In addition to providing certain nutrients, intake of probiotics and prebiotics is also important for improving human health and preventing diet-related diseases. However, the intake of beneficial biomass in natural foods is far from sufficient and needs to be enriched in the form of food products (Florowska et al., 2016); dairy products are important carriers of beneficial biomass.

Studies have concluded that yogurt consumption has the potential to improve intestinal health, ameliorate lactose intolerance, and prevent constipation (Adolfsson et al., 2004). Oh et al. (2016) found that adding a synbiotic combination of Lactobacillus gasseri 505 and Cudrania tricuspidata leaf extract to fermented milk could prevent liver toxicity in mice. However, the lack of research on the mechanism of action of probiotics and prebiotics has limited their application and development in dairy products. Consequently, it is imperative to conduct more research on microecological preparations, especially in probiotics and prebiotics.

This study investigated the recovery of intestinal microbes in 2 modes of regulation induced by ampicillin sodium in mice after the imbalance of intestinal microbiota. The first method was natural recovery and the second method was to add probiotics (Lactobacillus delbrueckii ssp. bulgaricus ATCC 11842 and Lactobacillus rhamnosus AS 1.2466) or emerging prebiotics [xylooligosaccharide (XOS) and red ginseng extracts (RGE)]. We found that, to varying degrees, the 4 additives rapidly improved the intestinal microbiota struc- ture of disordered mice and could specifically restore different kinds of microorganisms in the GIT. Each of the supplemental methods corresponded to specific beneficial microorganisms in the GIT. Therefore, in the next experiment, we used different combinations of prebiotics and L. rhamnosus to explore the effects of different prebiotics on the growth ability of probiotics, and the combination of XOS and L. rhamnosus was used to explore the effects of different ratios of synbiotics on the colonization ability of $L$. rhamnosus. This is of significance for our future research on individual differences and personalized supplementation of probiotics and prebiotics to achieve accurate restoration of intestinal balance, and is beneficial to the development and promotion of functional fermented milk in the future.

\section{MATERIALS AND METHODS}

\section{Probiotics and Prebiotics}

Lactobacillus rhamnosus AS $1.2466^{\mathrm{T}}$ and L. delbrueckii ssp. bulgaricus ATCC 11842 were sourced from the China General Microorganisms Collection, and Escherichia coli DH5 $\alpha$ (pMG36e-dsred2) was used from the preserved stock of our laboratory. The fructooligosaccharide (FOS), oligo-isomaltose (IMO), XOS, and inulin were obtained from Baolingbao Biotech Co. Ltd. (Hebei Province, China). The red ginseng was from the Pu Kang Pharmacy (Baoding, Hebei Province, China). To obtain RGE, $100 \mathrm{~g}$ of red ginseng was steeped in 200 $\mathrm{mL}$ of distilled water overnight. Then, it was incubated in a water bath at $95^{\circ} \mathrm{C}$ for $3 \mathrm{~h}$ and filtered. The process was repeated once. Plasmid pMG36e-dsred2 used in this study was constructed in our laboratory.

\section{Functional Evaluation of Probiotics and Prebiotics In Vitro}

For probiotics, the ability to tolerate gastrointestinal fluids and their ability to colonize the intestinal tract are key factors affecting their proposed health effects, and prebiotics can be effectively used by probiotics to promote the growth of probiotics. According to the method reported by Ouwehand et al. (1999), in vitro adhesion and tolerability tests were carried out. Single colonies of L. rhamnosus and L. bulgaricus were picked and added to $10 \mathrm{~mL}$ of liquid de Man, Rogosa, and Sharpe (MRS), incubated at $37^{\circ} \mathrm{C}$ (L. rhamnosus) or $42^{\circ} \mathrm{C}$ (L. bulgaricus) for $16 \mathrm{~h}$, and centrifuged at 14,000 $\times g$ for $5 \mathrm{~min}$ to collect the bacteria. At $10^{9} \mathrm{cfu} / \mathrm{mL}$ (turbidimetric method, adjusting the concentration of bacteria solution with PBS), $1 \mathrm{~mL}$ of the bacterial solution was inoculated into $9 \mathrm{~mL}$ of simulated gastric juice ( $\mathrm{pH} 3.0$ PBS with a pepsin concentration of $3.0 \mathrm{~g} / \mathrm{L}$ ), 
placed in a $37^{\circ} \mathrm{C}$ incubator, and $1 \mathrm{~mL}$ was diluted at 0 and $2 \mathrm{~h}$ for gradient dilution, and spread on MRS solid culture dishes. Then, the number surviving was measured and the survival rate was calculated (the ratio of microorganisms after and before treatment). Then, $1 \mathrm{~mL}$ of the culture digested in simulated gastric juice for $2 \mathrm{~h}$ was inoculated into $9 \mathrm{~mL}$ of simulated intestinal juice (trypsin concentration $1.0 \mathrm{~g} / \mathrm{L}$ PBS, $\mathrm{pH} 8.0$ ), digested in a $37^{\circ} \mathrm{C}$ incubator for $4 \mathrm{~h}$, and the survival rate was calculated as above. One milliliter of the culture digested in simulated intestinal juice for 4 $\mathrm{h}$ was inoculated into $9 \mathrm{~mL}$ of $0.3 \%$ bile salt solution, digested in a $37^{\circ} \mathrm{C}$ incubator for $3 \mathrm{~h}$, and the survival rate was calculated as above.

The inner surface of the intestinal tract of healthy mice was scraped, mixed with HEPES-Hanks' buffer $(10 \mathrm{mmol} / \mathrm{L}, \mathrm{pH} 7.4)$, centrifuged at 14,000 $\times \mathrm{g}$ and $4^{\circ} \mathrm{Cfor} 15 \mathrm{~min}$, and precipitated as cell and tissue debris. Using $1 \mathrm{mg} / \mathrm{mL}$ BSA as the standard, we adjusted the mucin concentration to about $1.0 \mathrm{mg} / \mathrm{mL}$, added 100 $\mu \mathrm{L} /$ well of the adjusted mucin to a 96 -well cell culture plate, and allowed the mucin proteins to be immobilized on cell culture plates overnight in a refrigerator at $4^{\circ} \mathrm{C}$. Then, 200 to $250 \mu \mathrm{L}$ of HEPES-Hanks' buffer was added and washed in the 96-well plate twice to remove unfixed mucus protein. Then, $100 \mu \mathrm{L}$ of L rhamnosus or L. bulgaricus suspension at a concentration of $10^{9}$ $\mathrm{cfu} / \mathrm{mL}$ was added to each well and incubated at $37^{\circ} \mathrm{C}$ for $1 \mathrm{~h}$. Then, the wells were rinsed 2 to 3 times with HEPES-Hanks' buffer solution to remove nonadherent bacteria. Finally, 200 to $250 \mu \mathrm{L}$ of lysate containing $1 \%$ SDS- $0.1 \mathrm{~mol} / \mathrm{L} \mathrm{NaOH}$ was added to release and dissolve the adherent bacteria, and lysed at $37^{\circ} \mathrm{C}$ for $0.5 \mathrm{~h}$. After the gradient dilution, the live bacteria were counted, and the adhesion rate was calculated.

The growth curves of L. rhamnosus and L. bulgaricus, respectively, in basal medium and Jerusalem basal medium were obtained by turbidimetry and viable count method. We confirmed that the 2 strains reached the end of logarithmic growth at 14 and $16 \mathrm{~h}$, respectively. The 2 strains were inoculated into the basal medium/ Jerusalem basal medium containing different amounts of XOS or RGE according to the inoculation amount of $1 \%$ (vol/vol) and incubated at $37^{\circ} \mathrm{C} / 42^{\circ} \mathrm{C}$ until the end of logarithmic growth. We determined the absorbance at $600 \mathrm{~nm}$ of cultures in the logarithmic growth phase of the strains to evaluate the proliferative effects of $\mathrm{XOS}$ and RGE, and the survival rate was calculated as described above.

\section{Animals, Diets, and Sample Preparation}

All animal procedures were done following an approved protocol from the Animal Welfare and Ethical
Committee of Agricultural University of Hebei, China, and were performed according to the ethical guidelines of the European Community guidelines (Directive 2010/63/EU; Wang et al., 2017). Specific-pathogen-free male Balb/c mice (4 wk old; Beijing Weitong Lihua Experimental Animal Technology Co. Ltd., Beijing, China) were housed in a temperature-controlled room $\left(26 \pm 1^{\circ} \mathrm{C}\right.$ and relative humidity of $\left.40-70 \%\right)$ with $12-\mathrm{h}$ light/dark cycles. All mice had free access to drinking water.

After 1 wk of adaptation, the mice were randomly divided into 6 groups (12 rats/group) as follows: control group $(\mathbf{C O N})$, natural recovery group (NR), $L$. bulgaricus group $(\mathbf{L B})$, L. rhamnosus group $(\mathbf{L R})$, XOS group, and RGE group, where 0,7 , and 14 in the treatment group names indicate 0,7 , and $14 \mathrm{~d}$ after successful modeling. The CON group was given sterile saline, and the other groups were given $125 \mathrm{mg} / \mathrm{mL}$ ampicillin sodium; the dosage volume was $0.2 \mathrm{~mL} / 10$ $\mathrm{g}$, twice a day for $4 \mathrm{~d}$, for modeling. After successful modeling, the NR group underwent natural recovery with sterile saline. The LB and LR groups were administered an equal volume of $10^{8} \mathrm{cfu} / \mathrm{mL}$ of $L$. bulgaricus suspension and $10^{9} \mathrm{cfu} / \mathrm{mL}$ of L. rhamnosus suspension, respectively; the XOS group was given a single dose of $0.23 \mathrm{~g}$ of XOS $/ \mathrm{kg}$ of BW, and the RGE group was given $4 \mathrm{~g}$ of RGE $/ \mathrm{kg}$ of BW once a day for 14 consecutive days. Mice were killed on d 0, 7, and 14 after successful modeling, and the cecal contents of the mice were collected aseptically.

\section{Cecal Bacterial DNA Extraction}

For cecal bacterial DNA extraction, $0.1 \mathrm{~g}$ of cecal sample was mixed with $5 \mathrm{~mL}$ of sterile PBS. The bacterial components were separated by differential centrifugation according to Apajalahti et al. (1998).

\section{S rRNA Gene PCR Amplification and Sequencing}

The V3-V4 hypervariable region of the 16S rRNA gene of each sample was amplified using primers 338 forward (5'-ACTCCTACGGGAGGCAGCAG-3') and 806 reverse (5'-GGACTACHVGGGTWTCTAAT-3'; $\mathrm{Xu}$ et al., 2016). The PCR amplification system consisted of $2 \mu \mathrm{L}$ of $2.5 \mathrm{mM}$ dNTP, $0.8 \mu \mathrm{L}$ of each primer $(5 \mu M), 2 \mu \mathrm{L}$ of $10 \times$ FastPfu buffer, $0.2 \mu \mathrm{L}$ of FastPfu polymerase (TransGen Biotech, Beijing, China), and $10 \mathrm{ng}$ of template DNA. The PCR amplification was carried out in a thermocycler PCR system (GeneAmp 9700, Applied Biosystems, Foster City, CA) using the following procedure: denaturation at $95^{\circ} \mathrm{C}$ for $3 \mathrm{~min}$, 30 cycles at $95^{\circ} \mathrm{C}$ for $30 \mathrm{~s}, 56^{\circ} \mathrm{C}$ for $30 \mathrm{~s}$, and $72^{\circ} \mathrm{C}$ for $45 \mathrm{~s}$, and finally the total extension was carried out at 
$72^{\circ} \mathrm{C}$ for $10 \mathrm{~min}$ and the resulting PCR product was examined on a $2 \%$ agarose gel. The amplified products were purified using an AxyPrep DNA Gel Recovery Kit (Axygen Biosciences, Union City, CA) and quantified using a QuantiFluor-ST (Promega, Madison, WI) blue fluorescence quantification system, all according to the manufacturer's instructions. The purified library was sequenced by Majorbio Bio-Pharm Technology Co. Ltd. (Shanghai, China) on the MiSeq platform (Illumina, San Diego, CA).

\section{S rRNA Gene Analysis}

Raw Illumina FASTQ files were de-multiplexed, quality filtered, and analyzed using Quantitative Insights Into Microbial Ecology (QIIME; Pylro et al., 2014). Operational taxonomic units (OTU) were performed on nonrepeating sequences according to $97 \%$ similarity. Chimeras were removed in the clustering process to obtain representative sequences of OTU. All the optimized sequences to the OTU representative sequence were mapped and the sequences that had a similarity to the OTU sequence of more than $97 \%$ were selected (Schloss et al., 2011). Alpha diversity can reflect species abundance and diversity in environmental microbial communities. Alpha diversity is evaluated using Shannon index and abundance-based coverage estimator (ACE) index (Schloss et al., 2009). A heat map based on the relative abundance of OTU was generated using $\mathrm{R}$ packages (Ling et al., 2015). Redundancy analysis is a constraint correspondence analysis method, which is a principal component analysis that is environmentally constrained and is usually analyzed using Euclidean distance; the analysis method is built into the $\mathrm{R}$ language vegan package rda. Welch's $t$-test uses the $t$-distribution theory to infer the probability of a difference, so as to compare whether the difference between 2 averages is significant. This test can be selected when the 2 groups have different variances; one-way ANOVA can be used to test whether the mean of multiple groups of samples is the same. Through this analysis, it is possible to compare whether the distribution of species in 3 or more sample groups is significantly different, and then test the different species post-hoc to find the different sample groups in multiple groups (Liao et al., 2019).

\section{In Vitro Screening of Synbiotics}

Prebiotics can enhance the ability of probiotics to adhere and prolong the dwell time of bacteria in GIT, resulting in positive health effects (Celebioglu et al., 2017). This study used oligosaccharides commonly found in dairy products as emerging prebiotics. This study was based on high-throughput sequencing results, and red fluorescent protein-labeled L. rhamnosus was constructed according to the method described by $\mathrm{Li}$ et al. (2019). The activated labeled L. rhamnosus was inoculated with erythromycin $(1 \mu \mathrm{g} / \mathrm{mL})$ in an amount of $1 \%$ inoculum, and XOS and IMO $(0.4,0.8,1.2,1.6$, and $2.0 \%$ each), FOS $(1.2,1.6,2.0,2.4$, and $2.8 \%)$, and inulin $(0.2,0.4,0.6$, and $0.8 \%)$ of the basal medium, respectively, were added and cultured at $37^{\circ} \mathrm{C}$. Medium containing the corresponding prebiotics of the uninoculated strain was used as a blank control, samples were taken after 12, 14, and $16 \mathrm{~h}$, and the optical density (absorbance at $600 \mathrm{~nm}$ ) was measured. By comparing the enrichment effects of the 4 prebiotics, those with a good value-added effects on the test strains were screened out.

\section{In Vivo Persistence of Synbiotics}

The adaptation period of the mouse is as described in Animals, Diets, and Sample Preparation. According to the above experimental results, the mice were divided into 4 groups of 21 each and were continuously intragastrically administered for $14 \mathrm{~d}$ using a mixture of concentration of $2 \times 10^{9} \mathrm{cfu} / \mathrm{mL}$ labeled L. rhamnosus and different concentrations of XOS to determine the effect of XOS on the persistence of $L$. rhamnosus in the intestine of mice. The control group was given the same concentration of labeled L. rhamnosus, and the other groups were administered a low $(0.058 \mathrm{~g} / \mathrm{kg}$ of $\mathrm{BW})$, medium $(0.12 \mathrm{~g} / \mathrm{kg}$ of $\mathrm{BW})$, or high $(0.35 \mathrm{~g} / \mathrm{kg}$ of BW) dose of XOS. Three mice were killed each time after $7,14,15,20,25$, and $31 \mathrm{~d}$ of gavage, intestinal mucus samples were collected by scraping in the intestine gently and spread on MRS-containing erythromycin at $37^{\circ} \mathrm{C}$ for $48 \mathrm{~h}$, and the viable bacteria were counted. A total of 24 colonies were randomly picked from each plate for verification using PCR.

Primers were designed according to the relevant gene sequences of dsred2, namely: dsred2R: $5^{\prime}$-TCTAGACATGGCCTCCTCCGAGA-3'; dsred2F: 5'-CCCAAGCTTCTACAGGAACAGGTGG-3'. The PCR amplification was performed using conventional methods. The expected PCR product was $750 \mathrm{bp}$. The PCR amplification system consisted of $2 \mu \mathrm{L}$ of dNTP $(2.5 \mathrm{mmol} / \mathrm{L}), 1 \mu \mathrm{L}$ of bacterial solution template, 1 $\mu \mathrm{L}(10 \mathrm{~mol} / \mathrm{L})$ of primer dsred2F, $1 \mu \mathrm{L}(10 \mathrm{~mol} / \mathrm{L})$ of primer dsred $2 \mathrm{R}, 0.5 \mu \mathrm{L}(5 \mathrm{U} / \mu \mathrm{L})$ of Ex Taq enzyme, $2 \mu \mathrm{L}$ of 10 PCR Buffer (including $\mathrm{Mg}^{2+}$ ), and $12.5 \mu \mathrm{L}$ of double-distilled water. The PCR amplification was performed in a thermal cycling PCR system (GeneAmp 9700, Applied Biosystems, Foster City, CA). The steps were as follows: denaturation at $94^{\circ} \mathrm{C}$ for $5 \mathrm{~min}, 30$ 
cycles at $92^{\circ} \mathrm{C}$ for $5 \mathrm{~min}, 64^{\circ} \mathrm{C}$ for $1 \mathrm{~min}, 72^{\circ} \mathrm{C}$ for $1 \mathrm{~min}$, and finally the total extension was carried out at $72^{\circ} \mathrm{C}$ for $10 \mathrm{~min}$.

\section{RESULTS}

\section{Functional Evaluation of Probiotics and Prebiotics In Vitro}

In simulated stomach and intestinal environments, the survival rates of $L$. bulgaricus treated with simulated gastric juice, simulated intestinal juice, and bile salt were $79.4,13.6$, and $7.5 \%$, respectively. For $L$. rhamnosus, the survival rates were 88.2, 28.03, and $19.4 \%$, respectively (Figure 1A); both strains could tolerate simulated intestinal and gastric juice (survival counts $>10^{6} \mathrm{cfu} / \mathrm{mL}$ ). Because mouse intestinal mucus is mainly composed of proteins, this experiment used BSA as a control to study the ability of probiotics to adhere to mouse intestines. The results showed that $L$. bulgaricus had no adhesion ability, the adhesion rate of L. rhamnosus on mouse intestinal mucosa was $26.95 \%$, and the adhesion rate in BSA was $4.53 \%$, indicating that $L$. rhamnosus can better adhere to the intestine of mice, so that it may exist in the intestine for a longer time, allowing it to better exert its health effects. Lactobacillus rhamnosus and L. bulgaricus were cultured in basal medium (addition of XOS or RGE), and optical density at $600 \mathrm{~nm}$ was measured in the logarithmic growth phase. We found that XOS and RGE promoted the proliferation of both strains (Figure 1B, C), indicating that XOS and RGE have excellent prebiotic characteristics.

\section{Establishment of Intestinal Microbiota Imbalance Model and Its Natural Recovery}

The effects of ampicillin sodium on the GIT of mice are shown in Figure 2. After $4 \mathrm{~d}$ of antibiotics in mice, the mice had dull villi, mild diarrhea occurred, and the cecum of these mice was significantly larger than that of normal mice.

Multiple sequencing of the V3-V4 hypervariable region covering the $16 \mathrm{~S}$ rRNA gene was used to characterize the bacterial diversity of the cecal microbiota of each group of mice. The total number of bacterial OTUs of 42 samples was 1,405. The fragrance value and $\mathrm{ACE}$ value of each sample reached saturation, and the number of OTUs was abundant (Supplemental Table S1; https://doi.org/10.3168/jds.2019-18003). We found that the Shannon diversity curve (Supplemental Figure S1; https://doi.org/10.3168/jds.2019-18003) of each sample quickly reached saturation, and the ACE curve
(Supplemental Figure S2; https://doi.org/10.3168/jds .2019-18003) of each sample increased with the amount of sequencing data. These results indicated that the sequencing was close to saturation, covering most of the microbes in the sample; thus, the results accurately reflect the diversity of the sample.

To determine the effect of antibiotics on intestinal microbial diversity in mice, we detected differences in index group between the CON and NR0 groups (Figure $3 \mathrm{~A}$ ), revealing a significant difference in intestinal microbiota between them $(P \leq 0.001)$. Combined with mouse phenotypic results (Figure 2), we demonstrated that the mouse intestinal microbiota imbalance model was successfully established. Subsequently, we administered sterile saline to the mice to allow them to recover naturally. In the natural recovery process, the relative abundance of the intestinal microbiota of the mice on d 0 was significantly higher than that of the CON group, and the relative abundance on $\mathrm{d} 7$ decreased rapidly to below that of the CON group until d 14, when the relative abundance of intestinal microbiota was not significantly different from that of CON group (Figure 3A). Figure 3B shows that at the genus level, the points of the NR14 group were clustered together with the CON group, indicating that at the genus level, the intestinal microbes of the mouse returned to normal levels after $14 \mathrm{~d}$ of natural recovery. However, when the differences between the groups were tested at the species level (Figure 3C), it became clear that some of the microorganisms in the NR14 group did not return to normal (Supplemental Tables S2-S4; https://doi.org/ 10.3168/jds.2019-18003).

\section{Effects of Probiotics on the Intestinal Microbiota}

The structure of the host gut microbiota can be rapidly changed by oral administration of products containing Lactobacillus, such as yogurt and probiotic preparations (Ershidat and Mazahreh, 2009). Species composition relationship analysis was performed to determine the influence of oral probiotic on the intestinal dysbacteriosis in mice. Phylum-level analysis showed that the main microorganisms were Tenericutes, Actinobacteria, Cyanobacteria, Verrucomicrobia, Proteobacteria, Firmicutes, and Bacteroides. Removal of $L$. bulgaricus and L. rhamnosus by gavage revealed that Firmicutes/Bacteroidetes ratio (F/B) decreased rapidly in the NR7 group compared with CON7, whereas F/B significantly recovered in the LB7 and LR7 groups (Figure 4A).

Further analysis of the composition of each species at the genus level revealed that the microbial diversity of each group was rich, and some endemic bacteria were 

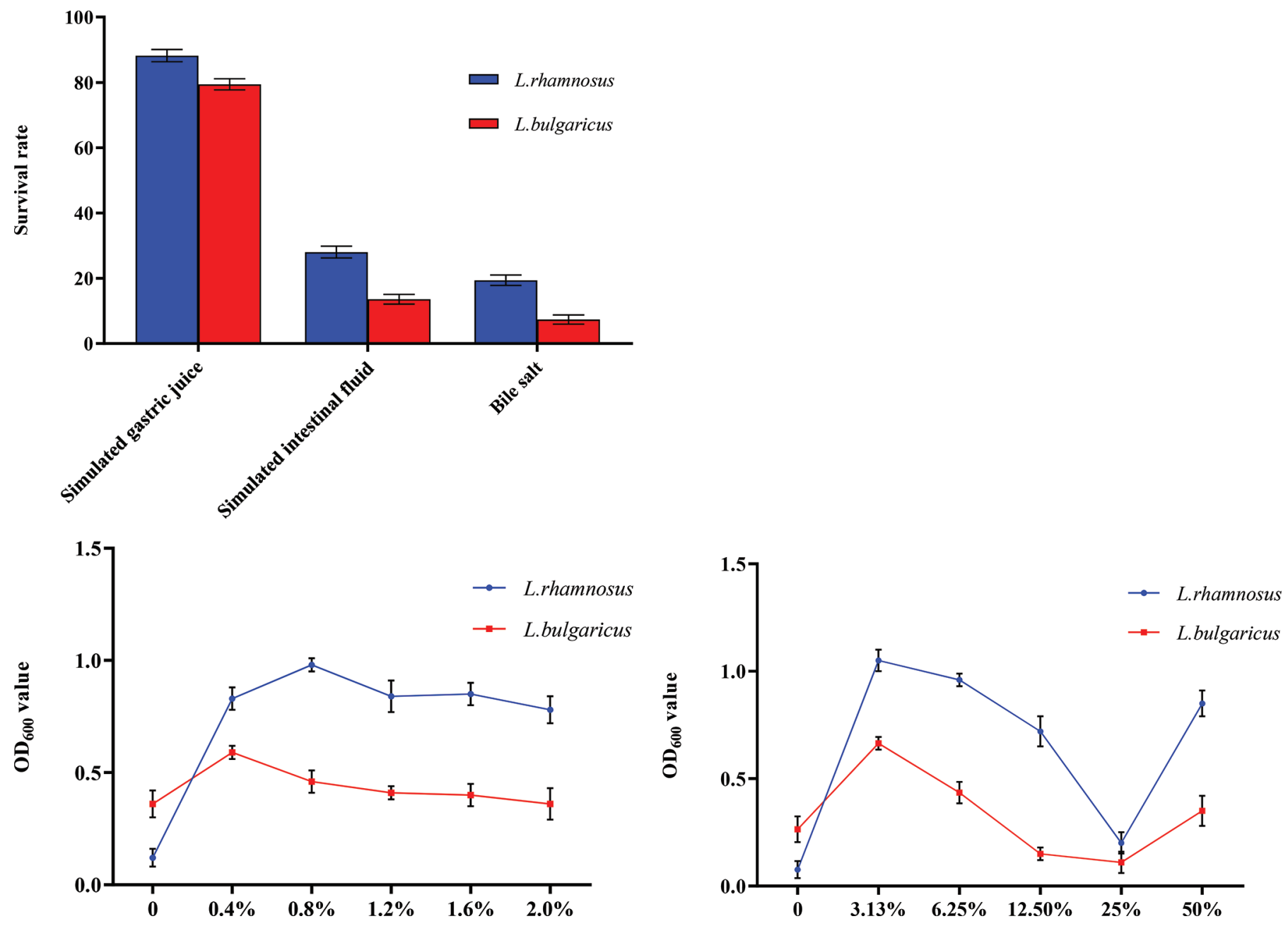

Figure 1. Functional evaluation of probiotics and prebiotics in vitro. (A) Lactobacillus rhamnosus and Lactobacillus bulgaricus; tolerance and ability to adhere to the intestine of mice. (B) Effect of xylooligosaccharides on the growth of L. rhamnosus and L. bulgaricus. (C) Effects of red ginseng extract on the growth of L. rhamnosus and L. bulgaricus. Values are expressed as mean $\pm \mathrm{SE}$. The optical density at $600 \mathrm{~nm}\left(\mathrm{OD}_{600}\right)$ value indicates the absorbance of $L$. rhamnosus and $L$. bulgaricus in the logarithmic growth phase.

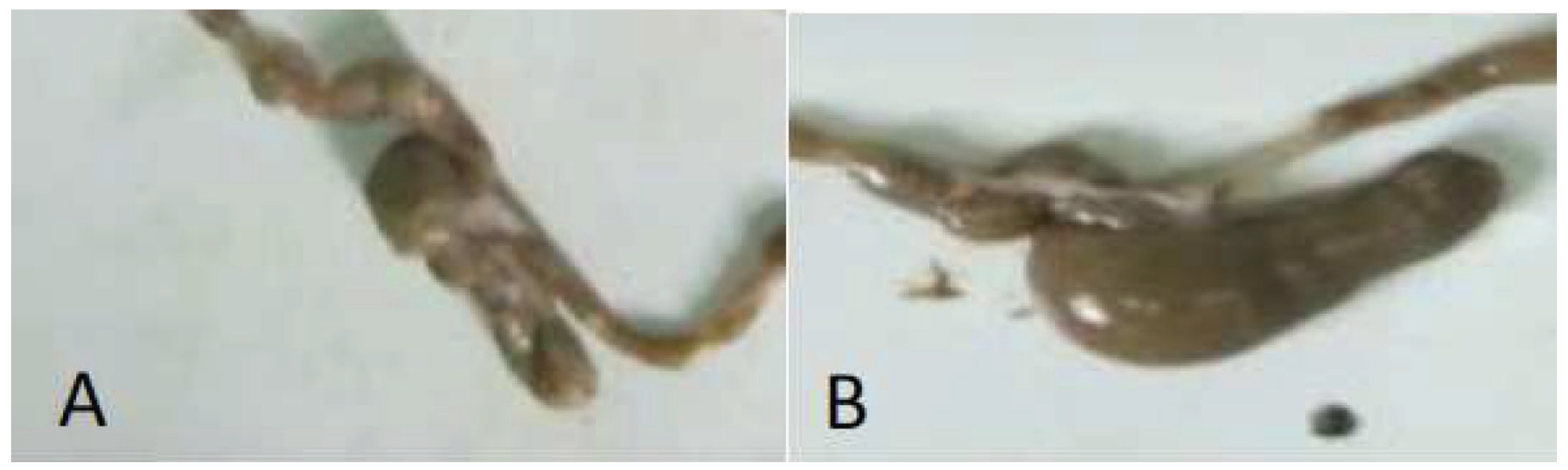

Figure 2. Establishment of a mouse intestinal microbiota imbalance model, showing anatomical changes in the cecum of (A) control group mouse, and (B) natural recovery $0 \mathrm{~d}$ group mouse. 
A

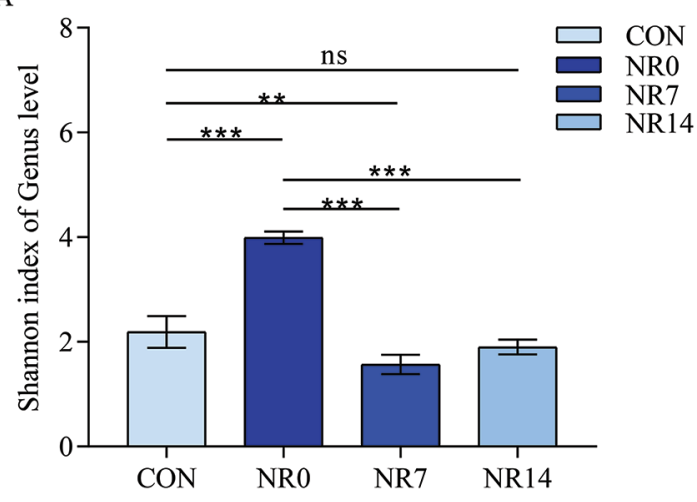

B

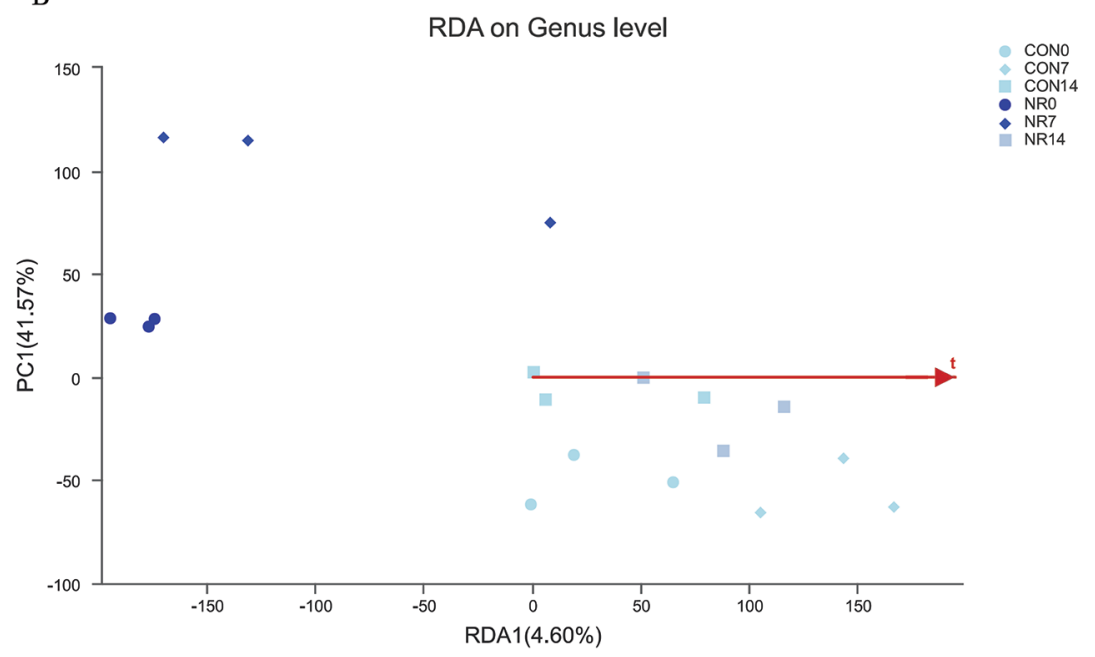

$\mathrm{C}$

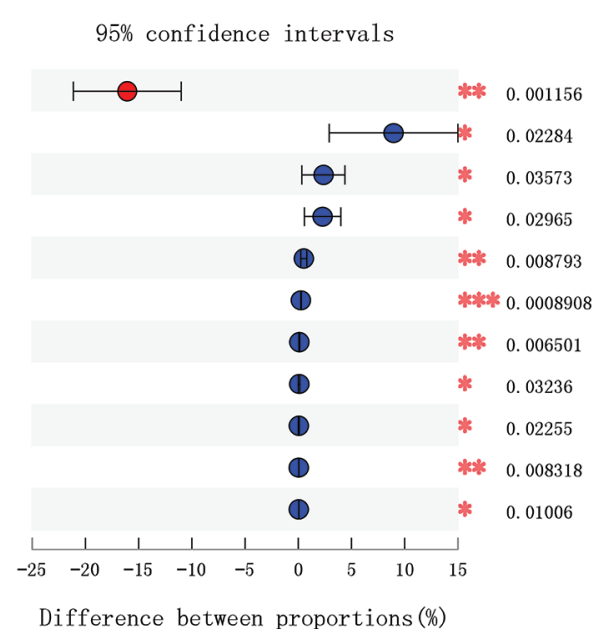

Figure 3. Establishment of a mouse intestinal microbiota imbalance model and its natural recovery. (A) Difference analysis between the control (CON) 14 d group, natural recovery $0 \mathrm{~d}$ (NR0) group, natural recovery $7 \mathrm{~d}$ (NR7) group, and natural recovery $14 \mathrm{~d}$ (NR14) index group. Error bars denote SD. (B) Redundancy analysis (RDA) on the genus level. (C) Welch's $t$-test bar plot on the species level; significant difference test between the CON group and NR14 group. The rightmost value is the $P$-value, ${ }^{*} 0.01<P \leq 0.05,{ }^{* *} 0.001<P \leq 0.01$, ${ }^{* * *} P \leq 0.001$. OTU $=$ operational taxonomic units.

different among the groups (Figure 4B, C). The typical harmful bacteria in the NR7 group, Klebsiella and Escherichia coli, had significantly higher relative abundance than the other groups, but the abundance of beneficial bacteria (Lactobacillus) was low $(P<0.001)$. After the probiotic intervention (compared with NR7 group), not only did traditional beneficial bacteria, Lactobacillus, recover significantly in the LB7 and LA7 groups $(P$ $<0.01$ ), but so did the recently discovered beneficial bacteria Akkermansia, Blautia, and Ruminaceae. Also, the abundance of harmful bacteria in these 2 groups (LB7 and LA7) was extremely low. This means that probiotics can quickly restore the abundance of beneficial bacteria in the GIT and inhibit harmful bacteria, helping to restore the intestinal microbiota imbalance caused by the antibiotic.

\section{Effects of Prebiotics on the Intestinal Microbiota}

Xylooligosaccharide is an emerging prebiotic, and RGE is a natural plant product that has been recognized as a novel prebiotic (Chen et al., 2015; Amorim et al., 2020). After administration of prebiotics, the analysis of the intestinal microbiota revealed that the $\mathrm{F} / \mathrm{B}$ in the XOS7 and RGE7 groups was restored. The abundance of beneficial bacteria such as Lactobacillus, Akkermansia, Blautia, and Ruminaceae in the 2 groups was higher than that in the NR7 group, although the difference was not statistically significant. However, the abundance of harmful bacteria such as Klebsiella and Escherichia coli was extremely low in both groups. In contrast to probiotic intervention, the richness of various genera in the family Lachnospiraceae in the NR7 
group was significantly lower $(P<0.01)$ than that in the CON, RGE7, and XOS7 groups. This suggests that probiotics and prebiotics regulate the intestinal microbial ecology in a similar manner, but the effects of probiotics and emerging prebiotics on the gut microbes have become more differentiated.
A
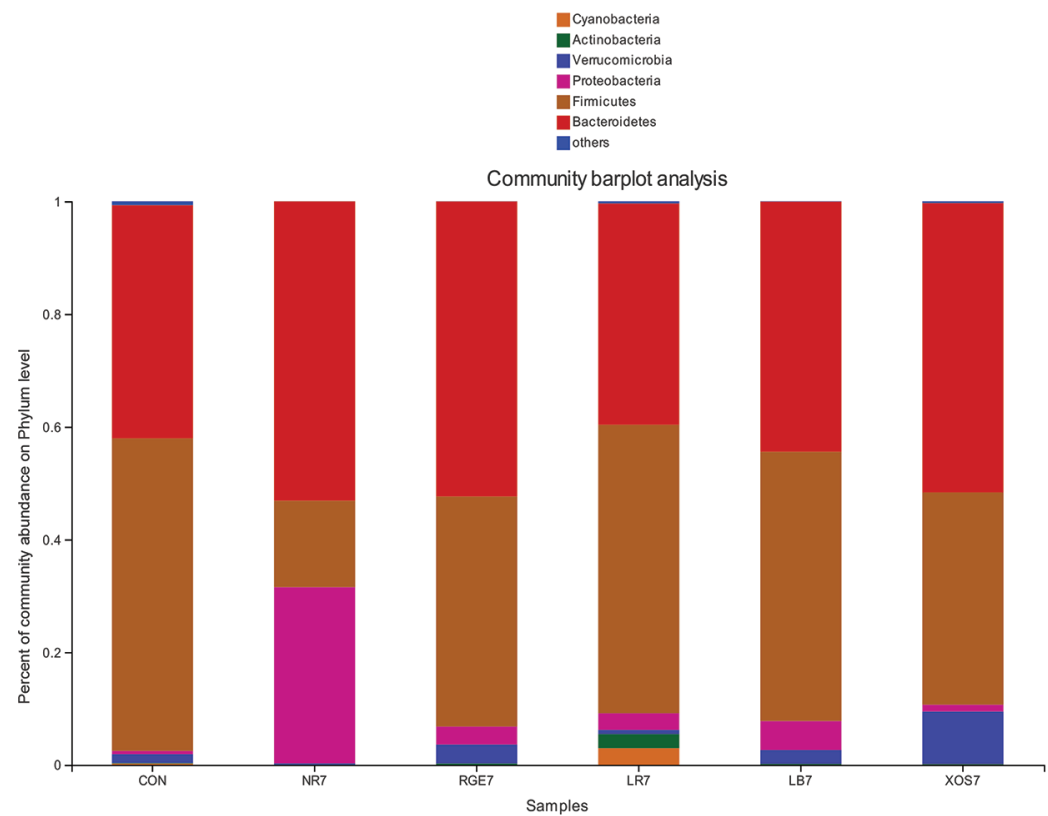
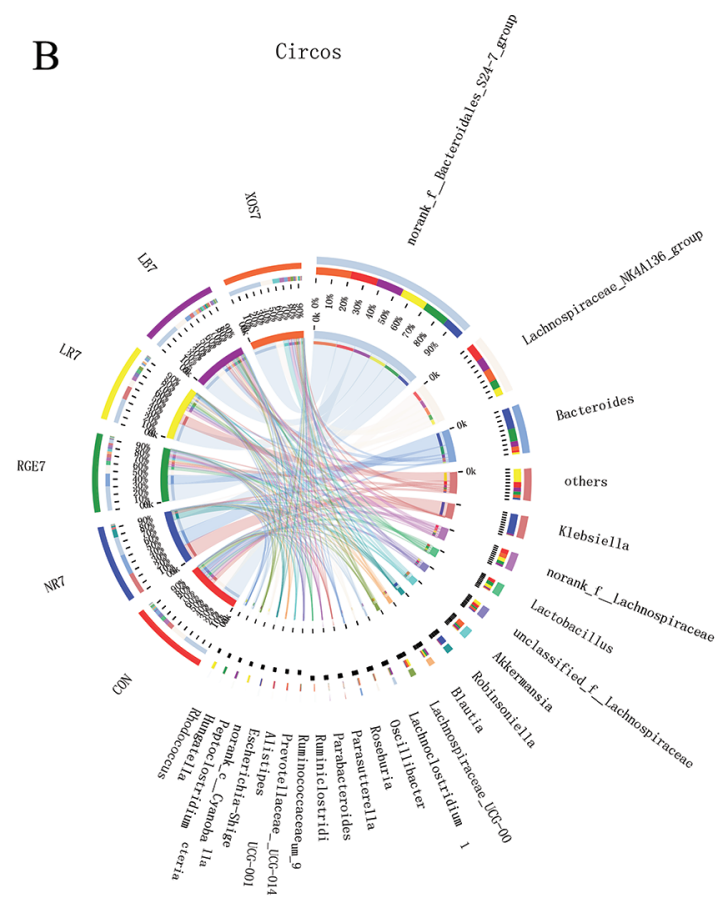

$\mathrm{C}$

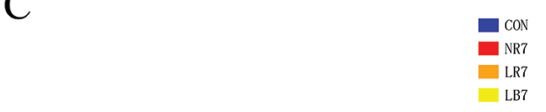

$\mathrm{D}$

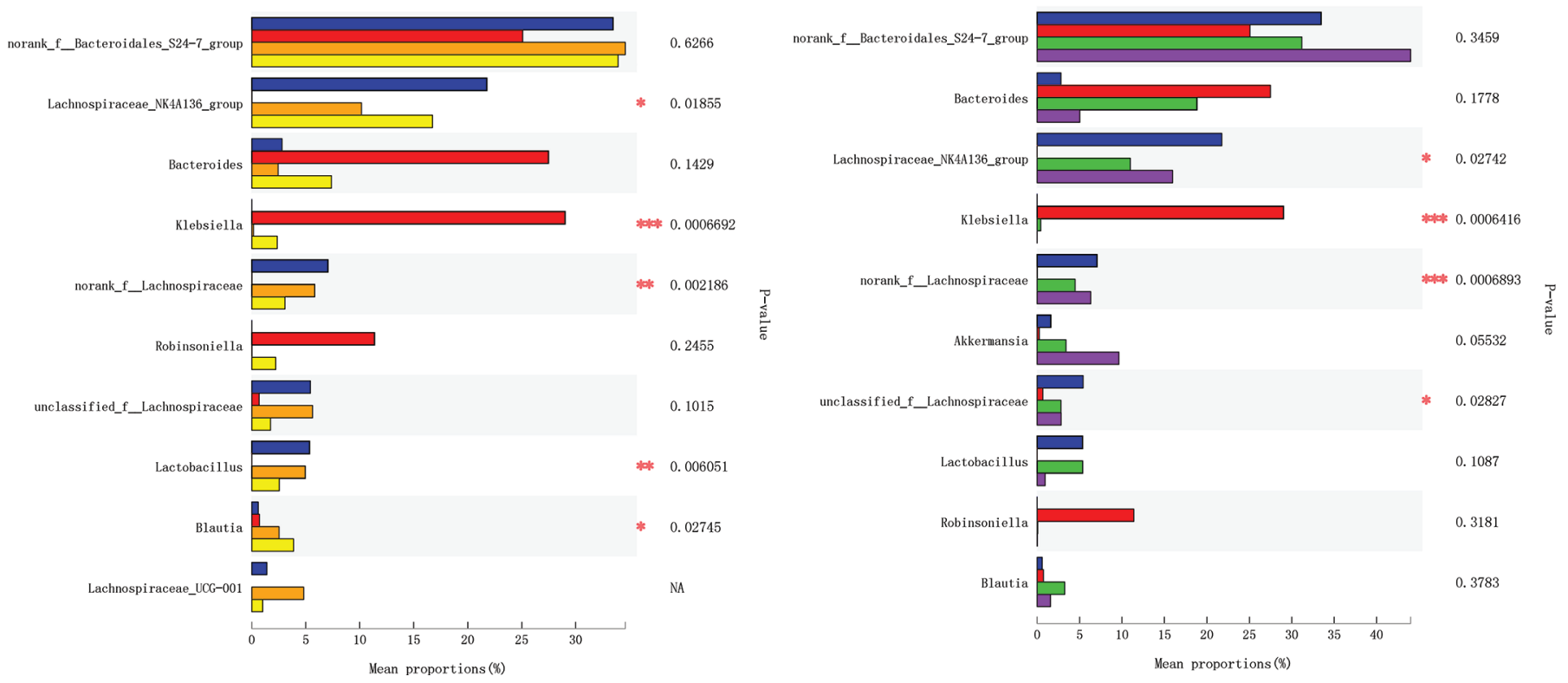

Figure 4. Lactobacillus regulates the structural changes of the intestinal microbiota of mice. (A) On d 7 of ingestion, the composition of the microbiota at the genus level of control (CON) group, natural recovery $7 \mathrm{~d}$ (NR7) group, Lactobacillus bulgaricus $7 \mathrm{~d}$ (LB7) group, Lactobacillus rhamnosus $7 \mathrm{~d}$ (LR7) group, xylooligosaccharide $7 \mathrm{~d}$ (XOS7) group, and red ginseng extract $7 \mathrm{~d}$ (RGE7) group. (B) On d 7 of ingestion, species relationship map at the phylum level of the CON, NR7, LB7, LR7, XOS7, and RGE7 groups. (C) On d 7 of ingestion, the differences of microbiota among the CON, NR7, LB7, and LR7 groups (one-way ANOVA). (D) On d 7 of ingestion, the differences of microbiota between the CON, NR7, XOS7, and RGE7 groups (one-way ANOVA). The rightmost value is the $P$-value, ${ }^{*} 0.01<P \leq 0.05, * * 0.001<P \leq 0.01, * * * P \leq 0.001$. 


\section{Analysis of Specific Strains of the Intestinal Microbiota of Mice}

To evaluate the effects of $L$. rhamnosus, L. bulgaricus, XOS, and RGE on the gut microbiota at the species level, we analyzed the relative abundance of the probiotics/prebiotics in different treatment groups after 14 $\mathrm{d}$ of intervention.

The relationship between supplements and intestinal microbes is complicated. Not all supplements had a significant effect on these gut microbes (Figure 5A). The supplements had different effects on intestinal microbes that cannot be recovered in a short time; when analyzing the interaction between gut microbes and different treatment groups (Figure 5B), we first mapped the interspecific relationships of 11 gut microbes based on $P$-value. On this basis, we observed the relative abundance of each microbe in different treatments; intestinal microbial abundance was low and higher than CON14 after $14 \mathrm{~d}$ of natural recovery and $14 \mathrm{~d}$ of supplementation intervention, respectively, and the relative abundance of intestinal microbes in the 14-d and CON14 groups was significantly restored. The intestinal microbial abundance was low/high above CON14 after $14 \mathrm{~d}$ of natural recovery, and the supplement intervention was $14 \mathrm{~d}$ higher/lower than CON14, indicating that the 4 supplements used in this experiment can restore the intestinal microbe imbalance caused by antibiotics. Among the gut microbes that cannot be recovered in a short time (Supplemental Table S3; https://doi .org/10.3168/jds.2019-18003), some were sensitive to 4 supplements, such as OTU1023, OTU1403, OTU288, and OTU232, whereas others were only sensitive to some supplements, such as OTU180 and OTU134. Neither OTU834 nor OTU172 was sensitive, and although these supplements can affect OTU834 and OTU172 by regulating other gut microbes, the effect was not significant. Therefore, differences were observed in the recovery of intestinal microbes in mice affected by different supplements.

\section{In Vitro Screening and In Vivo Persistence of Synbiotics}

The in vitro proliferation of probiotics indicated that different prebiotics had different proliferative effects on probiotics. After $12 \mathrm{~h}$ of culture of L. rhamnosus in 4 prebiotic media with different concentrations (added amounts were $1.2 \%$ XOS, $2.4 \%$ FOS, $1.6 \%$ IMO, and $0.4 \%$ inulin), the optical density (at $600 \mathrm{~nm}$ ) values were $0.891,0.877,0.438$, and 0.542 , respectively. Therefore, because XOS had the greatest proliferative effect, XOS mixed with labeled L. rhamnosus was administered to mice in the next experiment.
Figure 6 shows that the amount of XOS added in the synbiotic directly affected the persistence of $L$. rhamnosus in the intestine of mice; in the early stage of gavage, the addition of XOS promoted the persistence of $L$. rhamnosus. When the amount of XOS added was $0.058 \mathrm{~g} / \mathrm{kg}$ of BW (low-dose group), the synbiotics only proliferated until d 25, but low doses of XOS did not increase the persistence of $L$. rhamnosus after d 25 . Also, after $20 \mathrm{~d}$ of intragastric XOS addition at $0.12 \mathrm{~g} /$ $\mathrm{kg}$ of BW (medium- and high-dose group) of synbiotics, L. rhamnosus colonization in the mouse ileum was $7.48 \log \mathrm{cfu} / \mathrm{mL}$. The synbiotics showed a good ability to promote the persistence of L. rhamnosus, and this ability became more obvious after d 20. Interestingly, the medium- and high-dose groups showed similar persistence of $L$. rhamnosus. These results indicate that gavage of synbiotics can better promote the persistence of probiotics in the intestine than gavage of probiotics alone; XOS had the greatest effect when added at $0.12 \mathrm{~g} / \mathrm{kg}$ of BW. Not only can the health benefit of dairy products rich in synbiotics be guaranteed, but the production cost increase by adding prebiotics can be controlled to a certain extent.

\section{DISCUSSION}

In recent years, research on the characterization and verification of potential health benefits associated with the use of probiotics and prebiotics has increased significantly. Some researchers reported that the administration of a combination of L. rhamnosus and L. helveticus probiotics did not prevent the development of moderate to severe gastroenteritis (Freedman et al., 2018). However, the findings of Zhai et al. (2019) strongly suggest that low-fat yogurt fermented by Streptococcus thermophilus and L. bulgaricus can maintain intestinal barrier integrity. At present, it is unclear which probiotics affect the gut microbes, which makes it difficult to choose which probiotics to use to treat enteritis. Zhu et al. (2018b) claimed to accurately eliminate specific intestinal bacteria, which could improve colitis. To study the relationship between probiotics and human health, it is necessary to explore the correspondence between prebiotics and intestinal microorganisms. Similarly, Zhao et al. (2018) proposed the use of prebiotics that increase short-chain fatty acid production to prevent potential diseases associated with intestinal dysbiosis. So, probiotics and prebiotics have the same research value in this context.

Almost all experiments to evaluate gut microbiota mechanisms are conducted using in vitro and animal models, mostly rats and mice. Different inducers have been used depending on the study; for example, using a high-fat diet to feed normal mice and induce 
A

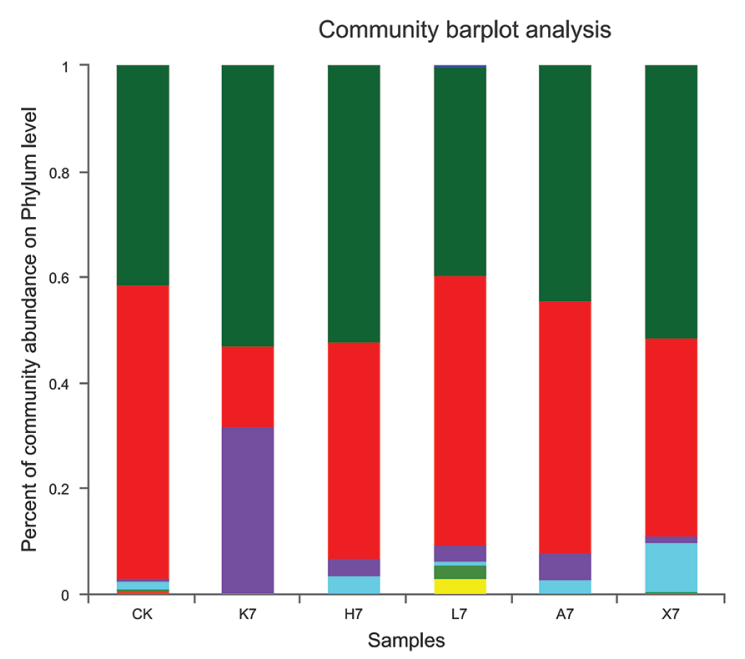

$\mathrm{C}$
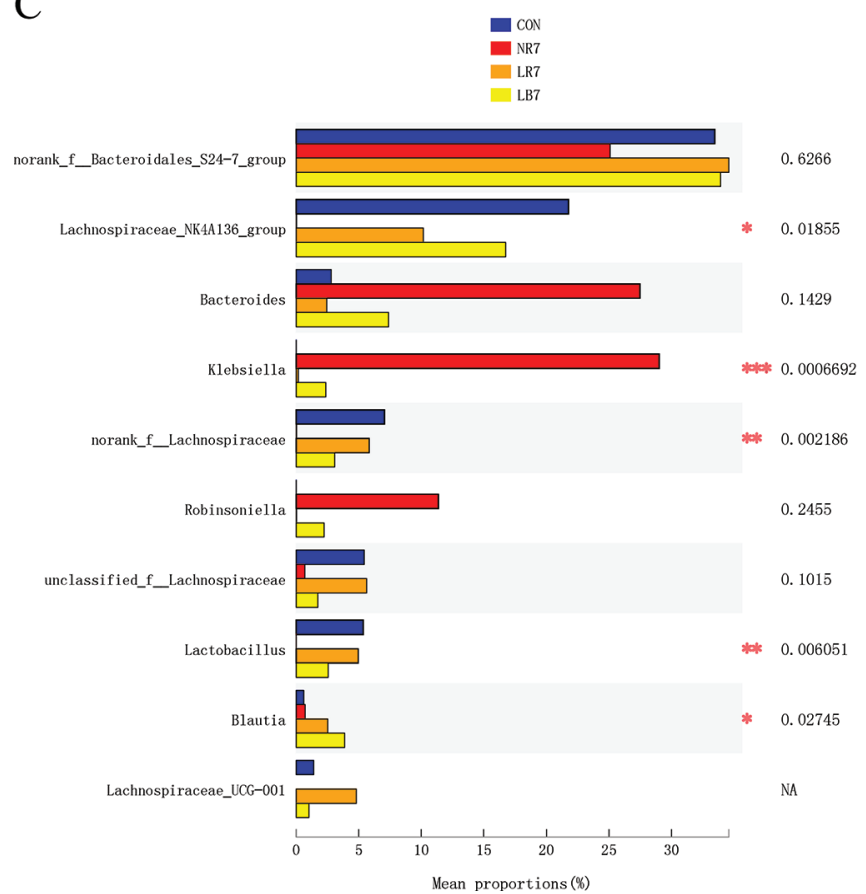

$\mathrm{B}$

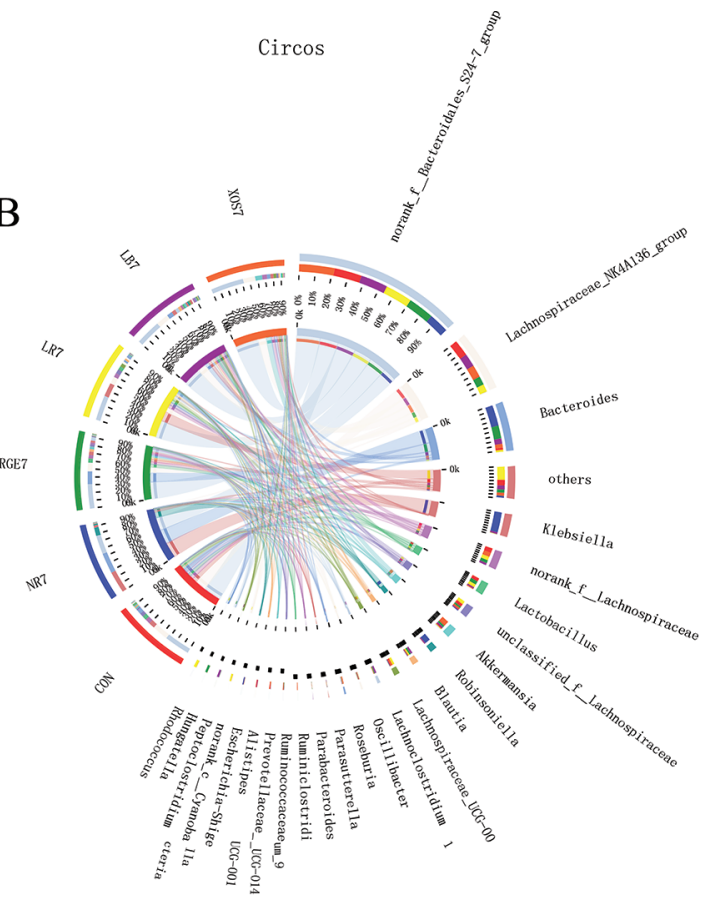

$\mathrm{D}$
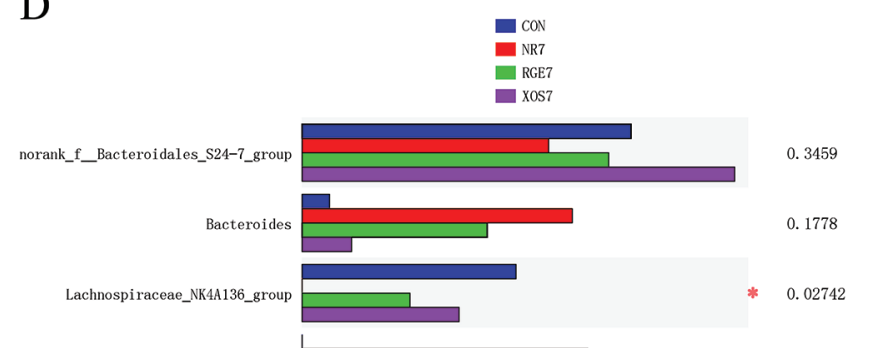

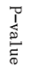

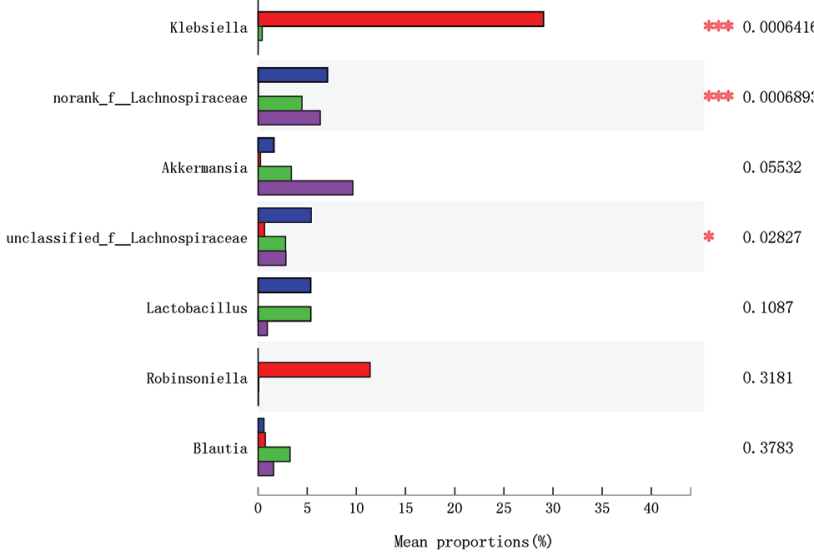

Figure 5. Effects of different treatments on intestinal microbes that cannot be naturally recovered in a short time. (A) Heat map displaying the relative abundance of operational taxonomic units (OTU) of the 11 microorganisms that cannot be naturally recovered in a short time in the 6 groups (CON14, NR14, LB14, LR14, RGE14, XOS14, where 14 indicates treatment for $14 \mathrm{~d}$ ). Relative abundance is based on the number of high-throughput sequencing reads clustering into each OTU after normalizing the number of reads per sample. Each column in the heat map represents one sample, and each row represents one genus. The relative abundance of each genus is indicated by a gradient of color from blue (low abundance) to red (high abundance). (B) Correlation network: specific OTU reversed by the different treatments are significantly correlated. Circle, the treatment of the supplement for $14 \mathrm{~d}$; diamond, OTU; red line, different treatment recovery OTU; blue line, negative correlation between OTU; green line, positive correlation between OTU. CON = control; $\mathrm{NR}=$ natural recovery group; LB = Lactobacillus bulgaricus treatment for $14 \mathrm{~d}$; $\mathrm{LR}=$ Lactobacillus rhamnosus treatment for $14 \mathrm{~d}$; XOS $=$ xylooligosaccharide treatment for $14 \mathrm{~d}$; RGE $=$ red ginseng hydrolysate treatment for $14 \mathrm{~d}$. 


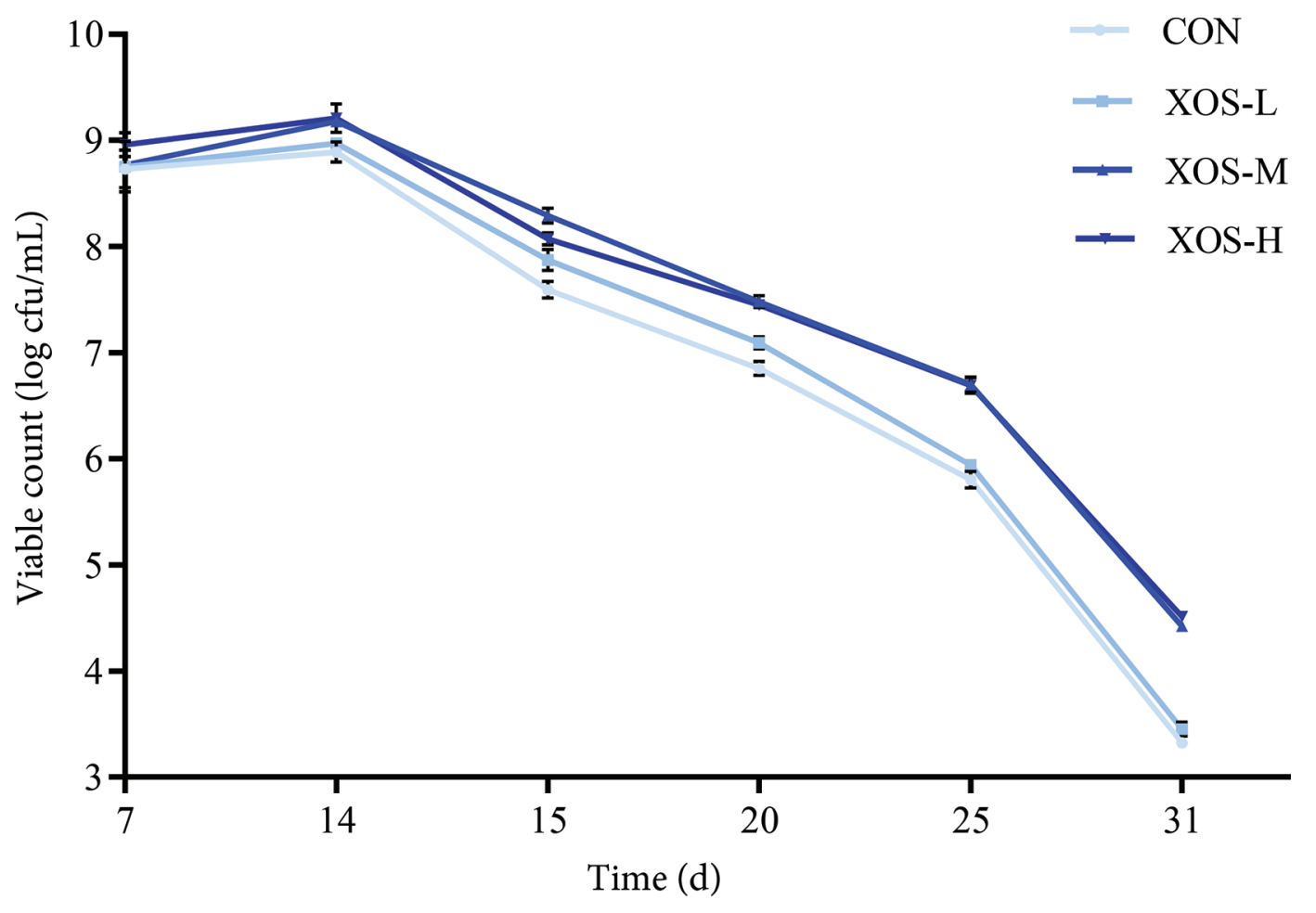

Figure 6. Effects of different doses of xylooligosaccharide (XOS) on the persistence of ileum in mice by Lactobacillus rhamnosus. CON = control; $\mathrm{L}=$ low dose; $\mathrm{M}=$ medium dose $\mathrm{H}=$ high dose. Error bars denote SD.

obese mouse models (Roh et al., 2017); using dextran sulfate sodium to induce mouse colitis (Xiong et al., 2019); and studying the effects of water-soluble polysaccharides from Schisandra chinensis on rats with antibiotic-associated diarrhea (Qi et al., 2019). Probiotics and prebiotics cannot restore serious damage to the intestinal tissue of mice caused by drugs such as dextran sulfate sodium but can regulate the intestinal microbiota imbalance caused by antibiotics in a short period. Therefore, this study used a common antibiotic, ampicillin sodium, to induce the mouse model.

Our results have shown that the intestinal microbiota imbalance caused by antibiotics can be restored to some extent by relying on the mouse's own immune regulation. We suspect that in the early stage of antibiotic modeling, intestinal probiotics were inhibited and the relative amount of low-abundance microbiota increased, which led to the relative abundance of intestinal microbiota in the NR0 group. After $7 \mathrm{~d}$ of natural recovery, some beneficial bacteria first proliferated and the relative abundance of some harmful microorganisms decreased, but the intestinal microbes remained unstable at this time. After d 14, as most of the beneficial bacteria recovered, the intestinal microbiota returned to stability.

The use of high-throughput sequencing of this study showed that the use of probiotics and prebiotics can ac- celerate the recovery of $\mathrm{F} / \mathrm{B}$ following antibiotic treatment. Other studies have discussed the significance of F/B; as reported by Parnell and Reimer (2012), microbial species measured in the Bacteroidetes division decrease, whereas those in the Firmicutes increase in obese rats. In addition, Liou and Turnbaugh (2012) indicated that antibiotics can cause obesity. This suggests that probiotics and prebiotics may be able to prevent obesity. In further experiments, emerging beneficial bacteria were found to change significantly; $7 \mathrm{~d}$ after the use of antibiotics, Blautia (Jenq et al., 2015), Ruminococcus (production of short-chain fatty acids; Minamida et al., 2005), Prevotellaceae (negatively correlated with host inflammation; Roelofsen et al., 2010; Vinolo et al., 2011; Ohira et al., 2013), Akkermansia and Parabacteroides (preventive epilepsy; Olson et al., 2018) were less abundant, but probiotics and prebiotics could effectively increase the abundance of these beneficial bacteria after $7 \mathrm{~d}$ of intervention. This indicates that probiotics and prebiotics increase beneficial intestinal microbes and inhibit harmful intestinal microbes to regulate intestinal microbiota imbalance caused by antibiotics.

In further experiments, we found that after $14 \mathrm{~d}$ of natural recovery in ampicillin-induced intestinal dysregulated mice, some intestinal microbes were unrecovered at the species level. Hildebrand et al. (2019) 
revealed that antibiotics can cause long-term changes in the intestinal microbes of some hosts; we hypothesize that the abundance of unrecovered intestinal microbes in this study may change over the long term; the intestinal microbes that cannot be naturally recovered in a short period can be restored to different extents under the action of different probiotics or prebiotics. However, some microorganisms remain unrecovered, so it is necessary to study the effects of more supplements on intestinal microbiota imbalance in preparation for targeted supplementation of intestinal microbiota. This study has some limitations; many of these specifically restored microorganisms are nonculturable microorganisms identified only by $16 \mathrm{~S}$ rRNA gene technology, and their relationship with human health is unclear. Many studies have been published recently on cultivability of "noncultivable" microorganisms. For example, Jung et al. (2014) used I-tip equipment to culture microorganisms that cannot be cultured by many traditional methods. This makes these gut microbes culturable and enables further study of their relationship to human health.

Numerous studies have shown that the use of synbiotic supplements has a more pronounced effect on the prevention and treatment of diseases than the use of a single probiotic and prebiotic supplement (Xue et al., 2017; Kim et al., 2018) but it is not clear whether all combinations of probiotics and prebiotics promote health. In this experiment, XOS was found to be superior to FOS, IMO, and inulin in promoting proliferation of L. rhamnosus, indicating that not all combinations of probiotics and prebiotics have the same effect, which is similar to the findings of Thiennimitr et al. (2018). We also found that XOS can better promote the metabolism of L. rhamnosus in mice and prolong its colonization time in vivo, which is similar to the finding of Celebioglu et al. (2017). In addition, when XOS reaches a certain concentration, the proliferation effect of $L$. rhamnosus is not obvious. Therefore, the synbiotic combination and the dose are important when developing fermented milk with new synbiotics. The study also found that the use of synbiotics in mice can increase the number of probiotics colonized in the intestine of mice and prolong their persistence in the intestine.

Today, probiotics and prebiotics are widely used in the dairy products (Ershidat and Mazahreh, 2009), and more evidence is needed to demonstrate the benefit to human health by probiotic, prebiotic, and synbiotic supplementation. In this study, we found that probiotics and prebiotics can effectively improve the intestinal microbiota imbalance. We showed that different treatments affect different intestinal microorganisms, which could be beneficial in developing dairy products for the intestinal environments of different people. In this study, we only studied L. rhamnosus, L. bulgaricus, RGE, and XOS; richer effects of other probiotic and prebiotic combinations on intestinal microbiota remain to be explored.

\section{CONCLUSIONS}

This study demonstrated that the use of probiotics (L. bulgaricus and L. rhamnosus) or emerging prebiotics (XOS and RGE) accelerated the recovery of intestinal microbiota (damaged by antibiotics) by allowing proliferation of beneficial bacteria and inhibition of harmful bacteria. In addition, when using different methods of intervention, different microbes in the intestine of mice are recovered. Synbiotics have greater probiotic functions than probiotics or prebiotics alone, and dairy products are excellent carriers for probiotics. Our research demonstrates the benefit of probiotics and prebiotics in the field of healthy foods, especially dairy products, and provides a theoretical basis for the development of functional foods.

\section{ACKNOWLEDGMENTS}

This work was supported by the National Natural Science Foundation of China (grant no. 31301520), the Natural Science Foundation of Hebei Province (grant no. C2016204129 and C2017204094; China), the Key Research and Development Program of Hebei Province (grant no. 19227134D; China), and the Chinese High Technology Program (863; grant no. 2006AA10Z317). All animal procedures followed the approved protocol from the Animal Welfare and Ethical Committee of Agricultural University of Hebei, China, and were performed according to the ethical guidelines of the European Community guidelines (Directive 2010/63/ EU). The authors declare that they have no competing interests.

\section{REFERENCES}

Adolfsson, O., S. N. Meydani, and R. M. Russell. 2004. Yogurt and gut function. Am. J. Clin. Nutr. 80:245-256. https://doi.org/10 $.1093 / \mathrm{ajcn} / 80.2 .245$.

Amorim, C., S. C. Silvério, B. B. Cardoso, J. I. Alves, M. A. Pereira, and L. R. Rodrigues. 2020. In vitro assessment of prebiotic properties of xylooligosaccharides produced by Bacillus subtilis 3610 . Carbohydr. Polym. 229:115460. https://doi.org/10.1016/j.carbpol .2019.115460.

Apajalahti, J. H., L. K. Särkilahti, B. R. Mäki, J. P. Heikkinen, P. H Nurminen, and W. E. Holben. 1998. Effective recovery of bacterial DNA and percent-guanine-plus-cytosine-based analysis of community structure in the gastrointestinal tract of broiler chickens. Appl. Environ. Microbiol. 64:4084-4088. https://doi.org/10.1128/ AEM.64.10.4084-4088.1998.

Celebioglu, H. U., S. V. Olesen, K. Prehn, S. J. Lahtinen, S. Brix, M. Abou Hachem, and B. Svensson. 2017. Mucin- and carbohydrate-stimulated adhesion and subproteome changes of the probi- 
otic bacterium, Lactobacillus acidophilus, NCFM. J. Proteomics 163:102-110. https://doi.org/10.1016/j.jprot.2017.05.015.

Chen, L., W. C. S. Tai, and W. L. W. Hsiao. 2015. Dietary saponins from four popular herbal tea exert prebiotic-like effects on gut microbiota in C57BL/6 mice. J. Funct. Foods 17:892-902. https:/ /doi.org/10.1016/j.jff.2015.06.050.

Ershidat, O. T. M., and A. S. Mazahreh. 2009. Probiotics bacteria in fermented dairy products. Pak. J. Nutr. 8:1107-1113. https://doi .org/10.3923/pjn.2009.1107.1113.

Florowska, A., K. Krygier, T. Florowski, and E. Dłużewska. 2016. Prebiotics as functional food ingredients preventing diet-related diseases. Food Funct. 7:2147-2155. https://doi.org/10.1039/ C5FO01459J.

Freedman, S. B., S. Williamson-Urquhart, K. J. Farion, S. Gouin, A. R. Willan, N. Poonai, K. Hurley, P. M. Sherman, Y. Finkelstein, B. E. Lee, X. L. Pang, L. Chui, D. Schnadower, J. Xie, M. Gorelick, and S. Schuh.PERC PROGUT Trial Group. 2018. Multicenter trial of a combination probiotic for children with gastroenteritis. N. Engl. J. Med. 379:2015-2026. https://doi.org/10 .1056/NEJMoa1802597.

Fuchs, S., G. Sontag, R. Stidl, V. Ehrlich, M. Kundi, and S. Knasmuller. 2008. Detoxification of patulin and ochratoxin A, two abundant mycotoxins, by lactic acid bacteria. Food Chem. Toxicol. 46:1398-1407. https://doi.org/10.1016/j.fct.2007.10.008.

Hildebrand, F., L. Moitinho-Silva, S. Blasche, M. T. Jahn, T. I. Gossmann, J. Huerta-Cepas, R. Hercog, M. Luetge, M. Bahram, A. Pryszlak, R. J. Alves, S. M. Waszak, A. Zhu, L. Ye, P. I. Costea, S. Aalvink, C. Belzer, S. K. Forslund, S. Sunagawa, U. Hentschel, C. Merten, K. R. Patil, V. Benes, and P. Bork. 2019. Antibiotics-induced monodominance of a novel gut bacterial order. Gut 68:1781-1790. https://doi.org/10.1136/gutjnl-2018-317715.

Jenq, R. R., Y. Taur, S. M. Devlin, D. M. Ponce, J. D. Goldberg, K. F. Ahr, E. R. Littmann, L. Ling, A. C. Gobourne, L. C. Miller, M. D. Docampo, J. U. Peled, N. Arpaia, J. R. Cross, T. K. Peets, M. A. Lumish, Y. Shono, J. A. Dudakov, H. Poeck, A. M. Hanash, J. N. Barker, M. A. Perales, S. A. Giralt, E. G. Pamer, and M. R. M. van den Brink. 2015. Intestinal Blautia is associated with reduced death from graft-versus-host disease. Biol. Blood Marrow Transplant. 21:1373-1383. https://doi.org/10.1016/j.bbmt.2015.04.016.

Jung, D., E. Y. Seo, S. S. Epstein, Y. Joung, J. Han, V. V. Parfenova, O. I. Belykh, A. S. Gladkikh, and T. S. Ahn. 2014. Application of a new cultivation technology, I-tip, for studying microbial diversity in freshwater sponges of Lake Baikal, Russia. FEMS Microbiol. Ecol. 90:417-423. https://doi.org/10.1111/1574-6941.12399.

Ke, X., A. Walker, S. B. Haange, I. Lagkouvardos, Y. W. Liu, P. Schmitt-Kopplin, M. von Bergen, N. Jehmlich, X. He, T. Clavel, and P. C. K. Cheung. 2019. Synbiotic-driven improvement of metabolic disturbances is associated with changes in the gut microbiome in diet-induced obese mice. Mol. Metab. 22:96-109. https:// doi.org/10.1016/j.molmet.2019.01.012.

Kim, Y. A., J. B. Keogh, and P. M. Clifton. 2018. Probiotics, prebiotics, synbiotics and insulin sensitivity. Nutr. Res. Rev. 31:37-51.

Konturek, P. C., I. A. Harsch, K. Konturek, M. Schink, and Y. Zopf. 2018. Gut-liver axis: How intestinal bacteria affect the liver. MMW Fortschr. Med. 160(S5):11-15. https://doi.org/10.1007/s15006-018 $-1051-6$.

Li, C., T. T. Bei, Z. H. Niu, X. Guo, M. S. Wang, H. Q. Lu, X. X. Gu, and H. T. Tian. 2019. Adhesion and persistence of the probiotic Lactobacillus rhamnosus labeled by Dsred2 in mouse gut. Curr. Microbiol. 76:896-903. https://doi.org/10.1007/s00284-019-01706 $-8$.

Liao, X. Y., L. Y. Song, B. H. Zeng, B. Y. Liu, Y. Y. Qiu, H. Qu, Y. Zheng, M. Long, H. D. Zhou, Y. Wang, Y. X. Du, J. Xu, R. F. Shen, Q. Tong, L. Q. Cai, X. Li, S. D. Guo, G. Y. Yang, Z. M. Zhu, X. Y. Pu, H. Wei, and H. T. Zheng. 2019. Alteration of gut microbiota induced by DPP-4i treatment improves glucose homeostasis. EBioMedicine 44:665-674. https://doi.org/10.1016/j.ebiom 2019.03.057

Ling, Z., X. Liu, X. Jia, Y. Cheng, Y. Luo, L. Yuan, Y. Wang, C. Zhao, S. Guo, L. Li, X. Xu, and C. Xiang. 2015. Impacts of infection with different toxigenic Clostridium difficile strains on faecal microbiota in children. Sci. Rep. 4:7485. https://doi.org/10.1038/srep07485.

Liou, A., and P. Turnbaugh. 2012. Antibiotic exposure promotes fat gain. Cell Metab. 16:408-410. https://doi.org/10.1016/j.cmet.2012 .09.009.

Mahasneh, S. A., and A. M. Mahasneh. 2017. Probiotics: A Promising role in dental health. Dent. J. (Basel) 5:26. https://doi.org/10 $.3390 /$ dj5040026.

Minamida, K., M. Kaneko, M. Ohashi, I. N. Sujaya, T. Sone, M. Wada, A. Yokota, H. Hara, K. Asano, and F. Tomita. 2005. Effects of difructose anhydride III (DFA III) administration on bile acids and growth of DFA III-assimilating bacterium Ruminococcus productus on rat intestine. J. Biosci. Bioeng. 99:548-554. https:// doi.org/10.1263/jbb.99.548.

Mohanty, D., S. Misra, S. Mohapatra, and P. S. Sahu. 2018. Prebiotics and synbiotics: Recent concepts in nutrition. Food Biosci. 26:152-160. https://doi.org/10.1016/j.fbio.2018.10.008.

Oh, N. S., J. Y. Lee, and Y. Kim. 2016. The growth kinetics and metabolic and antioxidant activities of the functional synbiotic combination of Lactobacillus gasseri 505 and Cudrania tricuspidata leaf extract. Appl. Microbiol. Biotechnol. 100:10095-10106. https: //doi.org/10.1007/s00253-016-7863-3.

Ohira, H., Y. Fujioka, C. Katagiri, R. Mamoto, M. Aoyama-Ishikawa, K. Amako, Y. Izumi, S. Nishiumi, M. Yoshida, M. Usami, and M. Ikeda. 2013. Butyrate attenuates inflammation and lipolysis generated by the interaction of adipocytes and macrophages. J. Atheroscler. Thromb. 20:425-442. https://doi.org/10.5551/jat.15065.

Olson, C. A., H. E. Vuong, J. M. Yano, Q. Y. Liang, D. J. Nusbaum, and E. Y. Hsiao. 2018. The gut microbiota mediates the antiseizure effects of the ketogenic diet. Cell 174:497. https://doi.org/ 10.1016/j.cell.2018.06.051.

Ouwehand, A. C., P. V. Kirjavainen, M. Grönlund, E. Isolauri, and S. J. Salminen. 1999. Adhesion of probiotic micro-organisms to intestinal mucus. Int. Dairy J. 9:623-630. https://doi.org/10.1016/ S0958-6946(99)00132-6.

Parnell, J. A., and R. A. Reimer. 2012. Prebiotic fibers dose-dependently increase satiety hormones and alter Bacteroidetes and Firmicutes in lean and obese JCR: LA-cp rats. Br. J. Nutr. 107:601613. https://doi.org/10.1017/S0007114511003163.

Pylro, V. S., L. F. Roesch, D. K. Morais, I. M. Clark, P. R. Hirsch, and M. R. Tótola. 2014. Data analysis for $16 \mathrm{~S}$ microbial profiling from different benchtop sequencing platforms. J. Microbiol. Methods 107:30-37. https://doi.org/10.1016/j.mimet.2014.08.018.

Qi, Y., L. Chen, K. Gao, Z. Shao, X. Huo, M. Hua, S. Liu, Y. Sun, and S. Li. 2019. Effects of Schisandra chinensis polysaccharides on rats with antibiotic-associated diarrhea. Int. J. Biol. Macromol. 124:627-634. https://doi.org/10.1016/j.ijbiomac.2018.11.250.

Roelofsen, H., M. G. Priebe, and R. J. Vonk. 2010. The interaction of short-chain fatty acids with adipose tissue: Relevance for prevention of type 2 diabetes. Benef. Microbes 1:433-437. https://doi .org/10.3920/BM2010.0028.

Roh, J. S., H. Lee, J. Lim, J. Kim, H. Yang, Y. Yoon, S. S. Shin, and M. Yoon. 2017. Effect of Gangjihwan on hepatic steatosis and inflammation in high fat diet-fed mice. J. Ethnopharmacol. 206:315-326. https://doi.org/10.1016/j.jep.2017.06.008.

Sanders, M. E. 2008. Probiotics: definition, sources, selection, and uses. Clin. Infect. Dis. 46(s2):S58-S61. https://doi.org/10.1086/ 523341.

Schloss, P. D., D. Gevers, and S. L. Westcott. 2011. Reducing the effects of PCR amplification and sequencing artifacts on 16S rRNAbased studies. PLoS One 6:e27310. https://doi.org/10.1371/ journal.pone.0027310.

Schloss, P. D., S. L. Westcott, T. Ryabin, J. R. Hall, M. Hartmann, E. B. Hollister, R. A. Lesniewski, B. B. Oakley, D. H. Parks, C. J. Robinson, J. W. Sahl, B. Stres, G. G. Thallinger, D. J. Van Horn, and C. F. Weber. 2009. Introducing mothur: Open-source, platform-independent, community-supported software for describing and comparing microbial communities. Appl. Environ. Microbiol. 75:7537-7541. https://doi.org/10.1128/AEM.01541-09. 
Sohail, M. U., M. Z. Shabbir, J. M. Steiner, S. Ahmad, Z. Kamran, H. Anwar, G. Hussain, A. Shaukat, M. I. Ullah, and J. S. Suchodolski. 2017. Molecular analysis of the gut microbiome of diabetic rats supplemented with prebiotic, probiotic, and synbiotic foods. Int. J. Diabetes Dev. Ctries. 37:419-425. https://doi.org/10.1007/ s13410-016-0502-9.

Thiennimitr, P., S. Yasom, W. Tunapong, T. Chunchai, K. Wanchai, A. Pongchaidecha, A. Lungkaphin, S. Sirilun, C. Chaiyasut, N. Chattipakorn, and S. C. Chattipakorn. 2018. Lactobacillus paracasei HII01, xylooligosaccharides, and synbiotics reduce gut disturbance in obese rats. Nutrition 54:40-47. https://doi.org/10.1016/ j.nut.2018.03.005.

Turek, S. 1960. The use of fractionated deproteinization of the blood serum for the determination of the soluble protein fractions. Clin. Chim. Acta 5:689-694. https://doi.org/10.1016/0009 -8981(60)90010-3.

Vinolo, M. A. R., H. G. Rodrigues, R. T. Nachbar, and R. Curi. 2011. Regulation of inflammation by short chain fatty acids. Nutrients 3:858-876. https://doi.org/10.3390/nu3100858.

Wang, L., L. Hu, S. Yan, T. Jiang, S. Fang, G. Wang, J. Zhao, H. Zhang, and W. Chen. 2017. Effects of different oligosaccharides at various dosages on the composition of gut microbiota and shortchain fatty acids in mice with constipation. Food Funct. 8:19661978. https://doi.org/10.1039/c7fo00031f.

Xiong, Y., X. D. Zhu, P. Wan, Y. P. Ren, C. Wang, R. W. Yan, Y. Guo, and A. P. Bai. 2019. Inhibition of ASM activity ameliorates DSS-induced colitis in mice. Prostaglandins Other Lipid Mediat. 140:26-30. https://doi.org/10.1016/j.prostaglandins.2018.12.002.

Xu, N., G. C. Tan, H. Y. Wang, and X. P. Gai. 2016. Effect of biochar additions to soil on nitrogen leaching, microbial biomass and bacterial community structure. Eur. J. Soil Biol. 74:1-8. https://doi .org/10.1016/j.ejsobi.2016.02.004.

Xue, Z. G., J. C. Yu, M. L. Zhao, W. M. Kang, and Z. Q. Ma. 2017. Effects of synbiotics on intestinal mucosal barrier in rat model. Clinical Nutrition Experimental 13:12-21. https://doi.org/10 .1016/j.yclnex.2017.02.001.
Zhai, Z. Y., J. J. Wang, B. Z. Huang, and S. Yin. 2019. Low-fat yogurt alleviates the pro-inflammatory cytokine IL-13-induced intestinal epithelial barrier dysfunction. J. Dairy Sci. 102:976-984. https:// doi.org/10.3168/jds.2018-15226.

Zhao, L., F. Zhang, X. Ding, G. Wu, Y. Y. Lam, X. Wang, H. Fu, X. Xue, C. Lu, J. Ma, L. Yu, C. Xu, Z. Ren, Y. Xu, S. Xu, H Shen, X. Zhu, Y. Shi, Q. Shen, W. Dong, R. Liu, Y. Ling, Y. Zeng, X. Wang, Q. Zhang, J. Wang, L. Wang, Y. Wu, B. Zeng, H. Wei, M. Zhang, Y. Peng, and C. Zhang. 2018. Gut bacteria selectively promoted by dietary fibers alleviate type 2 diabetes. Science 359:1151-1156. https://doi.org/10.1126/science.aao5774.

Zhu, C. S., R. Grandhi, T. T. Patterson, and S. E. Nicholson. 2018a. A review of traumatic brain injury and the gut microbiome: Insights into novel mechanisms of secondary brain injury and promising targets for neuroprotection. Brain Sci. 8:113. https://doi.org/10 $.3390 /$ brainsci8060113.

Zhu, W., M. G. Winter, M. X. Byndloss, L. Spiga, B. A. Duerkop, E. R. Hughes, L. Büttner, E. de Lima Romão, C. L. Behrendt, C. A. Lopez, L. Sifuentes-Dominguez, K. Huff-Hardy, R. P. Wilson, C. C. Gillis, C. Tükel, A. Y. Koh, E. Burstein, L. V. Hooper, A. J. Bäumler, and S. E. Winter. 2018b. Precision editing of the gut microbiota ameliorates colitis. Nature 553:208-211. https://doi.org/ 10.1038 /nature25172.

Zhu, X., Y. Han, J. Du, R. Z. Liu, K. T. Jin, and W. Yi. 2017. Microbiota-gut-brain axis and the central nervous system. Oncotarget 8:53829-53838. https://doi.org/10.18632/oncotarget.17754.

\section{ORCIDS}

Chen Li 주 https://orcid.org/0000-0001-6110-3714

Hongtao Tian ำ https://orcid.org/0000-0002-3079-0125

Rajesh Jha ๑ https://orcid.org/0000-0002-2891-8353 